\title{
Development of bacterial communities in biological soil crusts along a revegetation chronosequence in the Tengger Desert, northwest China
}

\author{
Lichao Liu ${ }^{1}$, Yubing Liu ${ }^{1,2}$, Peng Zhang ${ }^{1}$, Guang Song ${ }^{1}$, Rong Hui ${ }^{1}$, Zengru Wang ${ }^{1}$, and Jin Wang ${ }^{1,2}$ \\ ${ }^{1}$ Shapotou Desert Research \& Experiment Station, Northwest Institute of Eco-Environment and Resources, \\ Chinese Academy of Sciences, Lanzhou, 730000, China \\ ${ }^{2}$ Key Laboratory of Stress Physiology and Ecology in Cold and Arid Regions of Gansu Province, \\ Northwest Institute of Eco-Environment and Resources, Chinese Academy of Sciences, Lanzhou, 730000, China \\ Correspondence to: Yubing Liu (liuyb@lzb.ac.cn)
}

Received: 12 April 2017 - Discussion started: 18 April 2017

Revised: 12 July 2017 - Accepted: 19 July 2017 - Published: 23 August 2017

\begin{abstract}
Knowledge of structure and function of microbial communities in different successional stages of biological soil crusts (BSCs) is still scarce for desert areas. In this study, Illumina MiSeq sequencing was used to assess the compositional changes of bacterial communities in different ages of BSCs in the revegetation of Shapotou in the Tengger Desert. The most dominant phyla of bacterial communities shifted with the changed types of BSCs in the successional stages, from Firmicutes in mobile sand and physical crusts to Actinobacteria and Proteobacteria in BSCs, and the most dominant genera shifted from Bacillus, Enterococcus and Lactococcus to RB41_norank and JG34-KF-361_norank. Alpha diversity and quantitative real-time polymerase chain reaction (PCR) analysis indicated that bacterial richness and abundance reached their highest levels after 15 years of BSC development. Redundancy analysis showed that silt + clay content and total $\mathrm{K}$ were the prime determinants of the bacterial communities of BSCs. The results suggested that bacterial communities of BSCs recovered quickly with the improved soil physicochemical properties in the early stages of BSC succession. Changes in the bacterial community structure may be an important indicator in the biogeochemical cycling and nutrient storage in early successional stages of BSCs in desert ecosystems.
\end{abstract}

\section{Introduction}

Biological soil crusts (BSCs) are assemblages of cryptogamic species and microorganisms, such as cyanobacteria, green algae, diatoms, lichens, mosses, soil microbes and other related microorganisms that cement the surface soil particles through their hyphae, rhizines/rhizoids and secretions (Eldridge and Greene, 1994; Li, 2012; Pointing and Belnap, 2012; Weber et al., 2016). Due to their specialized structures and complicated assemblages of their members, BSCs constitute one of the most important landscapes and make up $40 \%$ of the living cover of desert ecosystems, even exceeding $75 \%$ in some special habitats (Belnap and Eldridge, 2003).

It is well known that BSCs play critical roles in the structure and function of semiarid and arid ecosystems (Eldridge and Greene, 1994; Li, 2012). They provide ecological services such as soil stabilization, reduction of wind and water erosion, and facilitation of higher plant colonization (Belnap, 2003; Belnap and Lange, 2001; Maier et al., 2014; Pointing and Belnap, 2012). BSCs are functionally important and variable, and may be a useful model system for diversityfunction research. Their functional attributes are relatively well known, and estimation and manipulation of biodiversity in experiments are feasible, at least within some groups of BSC biota (Bowker et al., 2010). This relationship is more easily interpreted in artificially constructed BSCs. There are primary successional stages for BSCs in desert ecosystems: mobile sand, algal crust, lichen crust and moss crust (Lan 
et al., 2012a; Liu et al., 2006). The different successional stages of BSCs vary in their ecological function (Belnap, 2006; Bowker et al., 2006b; Li, 2012; Moquin et al., 2012).

During BSC succession, physical crusts in mobile sand contain the lowest carbon $(\mathrm{C})$ and nitrogen $(\mathrm{N})$ contents (Zhang et al., 2009). Algal crust is the earliest stage; it has a thin surface layer composed of eolian-borne materials and an organic layer formed by filamentous cyanobacteria associated with sand particles (Housman et al., 2006; Zhang, 2005; Zhang et al., 2009). Lichen and moss appear following stabilization of the algal filaments on the soil surface. The $\mathrm{C}$ and $\mathrm{N}$ fixation rates are increased in lichen crust (Evans and Lange, 2003; Lan et al., 2012b; Zhang et al., 2010), and there is higher photosynthesis, exopolysaccharide and nitrogenase activity in moss crust than in the early successional crusts (Housman et al., 2006; Lan et al., 2012b). In the BSC successional process, the microbial composition and community structure change greatly ( $\mathrm{Hu}$ and Liu, 2003; Zhang et al., 2009). Crust succession is positively correlated with phospholipid fatty acid content and microbial biomass (Liu et al., 2013). The microbial biomass of soils is the greatest driving force in most terrestrial ecosystems, largely due to control of conversion rates and mineralization of organic matter (Albiach et al., 2000; Baldrian et al., 2010).

Bacteria present the highest proportion of the microbial biomass in BSCs (Bates et al., 2010; Green et al., 2008; Gundlapally and Garcia-Pichel, 2006; Maier et al., 2014; Wang et al., 2015) and thus have important roles in the BSC successional process. They can decompose organic material and release nutrients, mediating geochemical processes necessary for ecosystem functioning in the persistence of BSCs (Balser and Firestone, 2005). Species composition and community structure of bacteria change greatly during the successional process of BSCs (Gundlapally et al., 2006; Moquin et al., 2012; Zhang et al., 2016). Most research on prokaryotic diversity of BSCs has focused on cyanobacteriadominated biocrusts in arid and semiarid regions (Abed et al., 2010; Garcia-Pichel et al., 2001; Nagy et al., 2005; Steven et al., 2013; Yeager et al., 2004). Recent studies of the bacterial community structure of bryophyte- or lichendominated crusts indicate that lichen-associated communities encompass a wide taxonomic diversity of bacteria (Bates et al., 2011; Cardinale et al., 2008; Maier et al., 2014). Heterotrophic bacteria may perform a variety of roles such as nutrient mobilization and $\mathrm{N}$ fixation and could be of considerable importance for the stability of lichen-dominated soil communities. However, there have been few studies on changes of bacterial diversity and their function in BSCs during the development process in desert zones, and these have only focused on the Sonoran (Nagy et al., 2005) and Gurbantunggut deserts (Zhang et al., 2016). What changes occur in bacterial community composition and in their potential roles in improving soil properties for different BSC successional stages? What is the significance of these changes to BSC succession in the recovery process of desert revegetation in temperate zones?

Bowker (2007) examined the role of BSCs in primary succession (vs. secondary succession) during a time when resources were available (e.g., light); however, they became less important once higher vegetation took over. In some environments of high abiotic stress (e.g., deserts), BSCs play a role in succession but remain a permanent component. Bowker's review and discussion is supported by work performed in southern Africa (Büdel et al., 2009) in which different successional BSCs are described. Büdel et al. (2009) also describe in detail crust types that were representative of successional stages. Castillo-Monroy et al. (2011) showed few BSC effects on ecosystem function could be ascribed to bacteria.

A recent study on crusts in the Tengger Desert, China, showed that bacterial diversity and richness were highest after 15 years, and at least 15 years might be needed for recovery of bacterial abundance of BSCs (Liu et al., 2017). To better understand these questions, we must analyze in detail the bacterial community composition of BSCs at all levels of classification and their corresponding function in the recovery process of BSCs. In the present study, bacterial community composition and potential function were analyzed in BSCs along a chronosequence of over 50-year-old revegetation. We investigated the following questions. What are the drivers of bacterial composition over time? What are the micro-processes that drive bacterial composition and function? Do bacteria drive changes in soil physicochemical properties which in turn have a direct influence on bacterial composition and function?

\section{Materials and methods}

\subsection{Study site description}

The study site is located in Shapotou, at the southeast fringe of the Tengger Desert, northwest China. The natural landscape is characterized by the reticulated chains of barchan dunes with a vegetation cover of less than $1 \%$. The mean annual precipitation is about $180 \mathrm{~mm}$ with large seasonal and interannual variation. The mean wind speed is $3.5 \mathrm{~m} \mathrm{~s}^{-1}$, and on average $122 \mathrm{~d} \mathrm{yr}^{-1}$ days with dust events. The revegetation protection system for Bao-Lan railway in this area was established initially in 1956 and was expanded away from the railway in 1964, 1973, 1981 and 1987 through establishment of straw checkerboards and plantation of xerophilous shrubs. This unirrigated revegetation system has worked well in protecting the railroad line from sand burial and dust hazards for the past 60 years. Also, the experimental plots of less than 1 ha were established with the same plantation techniques by the Shapotou Desert Research and Experiment Station in 1987, 2000 and 2010 in the nearby sand dunes. These fixedsand areas provide an ideal temporal succession sequence 

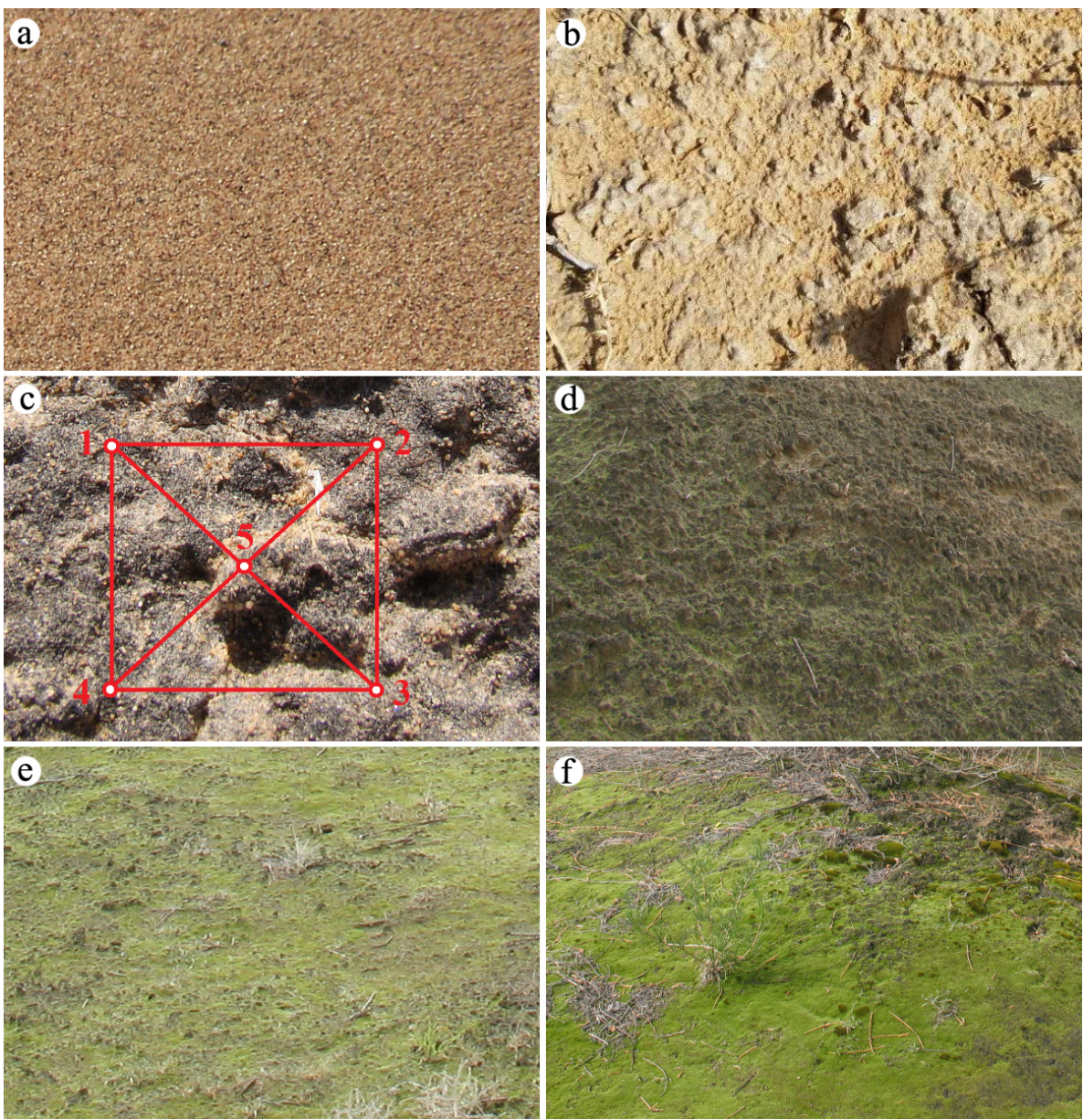

Figure 1. Sand dune landscape before (MS, a) and after establishing sand-binding vegetation with physical crusts dominated by few algae, revegetated in 2010 (5YR, b); with BSCs dominated by algae and lichens, revegetated in 2000 (15YR, c); with BSCs dominated by lichens and few mosses, revegetated in 1987 (28YR, d); with BSCs dominated by few lichens and mosses, revegetated in 1981 (34YR, e); and with BSCs dominated by mosses, revegetated in 1964 (51YR, f). Five soil cores ( $3.5 \mathrm{~cm}$ diameter) with crust layers from four vertices of a square (20 m length) and a diagonal crossing point in each plot were sampled individually (as shown in c).

for studying the variation in environmental factors. As mentioned in the literature, the initial state of BSCs begins to form following the stabilization of sand dunes and develop with the colonization of cryptogam (Liu et al., 2006). BSCs can be divided into four types: physical, algae-dominated, lichen-dominated and moss-dominated crusts. In this study, we selected the whole BSC layer from the revegetation established in 1964, 1981, 1987, 2000 and 2010, and non-fixed mobile sand (MS) as the control (Fig. 1). BSCs were sampled in early November 2015 and named according to the fixedsand time as 51YR (51 years of revegetation), 34YR, 28YR, $15 \mathrm{YR}, 5 \mathrm{YR}$ and MS, respectively. The main types of BSCs were algae-, lichen- and moss-dominated crusts from 15YR to 51YR.

\subsection{BSC sampling}

The detailed sampling method is shown in Fig. 1c, and BSCs were sampled individually using a sterile trowel. To decrease spatial heterogeneity, each BSC sample was taken from six individual plots (at least $20 \mathrm{~m}$ between two adjacent plots) from each revegetation time. Therefore, we obtained 30 BSC samples in total ( 5 cores $\times 6$ individual plots), and these were mixed together to form one composite BSC sample. Triplicate composite samples for each revegetation time were collected, and the BSC samples were preserved in an ice box. Samples were then taken back to the laboratory, immediately sieved (by $1 \mathrm{~mm}$ ) to remove stones and plant roots, homogenized thoroughly and stored at $-70^{\circ} \mathrm{C}$ for subsequent analyses. 


\subsection{DNA extraction and Illumina MiSeq sequencing}

Microbial DNA was extracted from BSC samples using E.Z.N.A Soil DNA (Omega Bio-tek, Norcross, GA, USA) according to the manufacturer's protocols. The extracted DNA was diluted in TE buffer $(10 \mathrm{mM}$ Tris- $\mathrm{HCl}$ and $1 \mathrm{mM}$ EDTA at $\mathrm{pH}$ 8.0) and stored at $-20^{\circ} \mathrm{C}$ until use. An aliquot of the extracted DNA from each sample was used as a template for amplification. The bacteria $16 \mathrm{~S}$ ribosomal RNA (rRNA) gene was amplified by polymerase chain reaction (PCR) $\left(95^{\circ} \mathrm{C}\right.$ for $3 \mathrm{~min}$; followed by $25 \mathrm{cy}$ cles at $95^{\circ} \mathrm{C}$ for $30 \mathrm{~s}, 55^{\circ} \mathrm{C}$ for $30 \mathrm{~s}$ and $72{ }^{\circ} \mathrm{C}$ for $45 \mathrm{~s}$; and a final extension at $72^{\circ} \mathrm{C}$ for $\left.10 \mathrm{~min}\right)$ using primers 338F (5'-ACTCCTACGGGAGGCAGCA-3') and 806R (5'GGACTACHVGGGTWTCTAAT- ${ }^{\prime}$ ). PCR analyses were performed in triplicate $20 \mu \mathrm{L}$ mixture containing $2 \mu \mathrm{L}$ of $5 \times$ FastPfu Buffer, $2 \mu \mathrm{L}$ of $2.5 \mathrm{mM}$ dNTPs, $0.8 \mu \mathrm{L}$ of each primer $(5 \mu \mathrm{M}), 0.2 \mu \mathrm{L}$ of FastPfu Polymerase and $10 \mathrm{ng}$ of template DNA. This was conducted according to Wang et al. (2015). Amplicons were extracted from $2 \%$ agarose gels and purified using the AxyPrep DNA Gel Extraction Kit (Axygen Biosciences, Union City, CA, USA) according to the manufacturer's instructions and quantified using QuantiFluor ${ }^{\mathrm{TM}}$-ST (Promega Corporation, Madison, WI, USA).

Purified amplicons were pooled in equimolar and pairedend sequenced $(2 \times 300)$ on an Illumina MiSeq platform according to the standard protocols at Majorbio Bio-Pharm Technology Co. Ltd., Shanghai, China (http:// www.majorbio.com). The raw reads were deposited in the NCBI Sequence Read Archive database (accession number: SRP091312).

\subsection{Quantitative real-time PCR (qPCR)}

qPCR was performed to determine the absolute 16S rRNA gene abundance. We used the primer sets of $515 \mathrm{~F}\left(5^{\prime}\right.$ GTGCCAGCMGCCGCGGTAA-3') and 806R to quantify the total bacterial populations. The standard templates were made from 10-fold dilutions of linearized plasmids containing the gene fragment of interest that was cloned from amplified pure culture DNA. The $20 \mu \mathrm{L}$ reaction mixtures contained $10 \mu \mathrm{L}$ of $2 \times$ SYBR mix (with ROX) (DBI Bioscience, Ludwigshafen, Germany), $0.4 \mu \mathrm{L}$ each of $10 \mu \mathrm{M}$ forward and reverse primers, $1 \mu \mathrm{L}$ of total DNA template $\left(1 \mathrm{ng} \mathrm{LL}^{-1}\right)$ and $8.2 \mu \mathrm{L}$ of RNase-free $\mathrm{ddH}_{2} \mathrm{O}$. The reaction was conducted on a Stratagene Mx3000P real-time PCR system (Stratagene, Agilent Technologies Inc., Santa Clara, CA, USA) using the following program: $94^{\circ} \mathrm{C}$ for $3 \mathrm{~min}$ followed by 40 cycles of $94^{\circ} \mathrm{C}$ for $30 \mathrm{~s}, 58^{\circ} \mathrm{C}$ for $30 \mathrm{~s}$ and $72^{\circ} \mathrm{C}$ for $30 \mathrm{~s}$, and then $72^{\circ} \mathrm{C}$ for $2 \mathrm{~min}$. The detection signal was collected at $72^{\circ} \mathrm{C}$ for $30 \mathrm{~s}$ and analyzed. The melting curve was obtained to confirm that the amplified products were of the appropriate size. For each soil sample, the qPCRs were repeated six times.

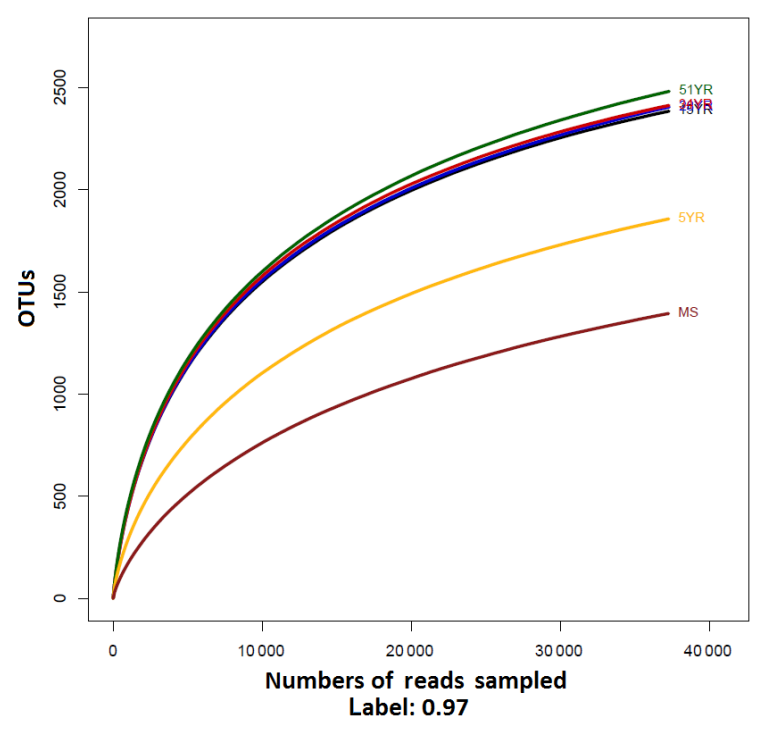

Figure 2. Rarefaction results of the 16S rDNA libraries based on $97 \%$ similarity in different age of BSCs. MS, 5YR, 15YR, 28YR, 34YR and 51YR represent mobile sand, 5-, 15-, 28-, 34- and 51year-old BSCs, respectively.

\subsection{Processing of sequencing data}

Raw FASTQ files were demultiplexed and quality-filtered using QIIME (version 1.17) with the following criteria: (i) the $300 \mathrm{bp}$ reads were truncated at any site receiving an average quality score $<20$ over a 50 bp sliding window, discarding the truncated reads shorter than $50 \mathrm{bp}$; (ii) there was exact barcode matching, with at most two mismatched nucleotides in primer matching, and reads containing ambiguous characters were removed; and (iii) only sequences that overlapped $>10 \mathrm{bp}$ were assembled according to their overlap sequence. Reads that could not be assembled were discarded.

Operational taxonomic units (OTUs) were clustered with $97 \%$ similarity cut-off using UPARSE (version $7.1 \mathrm{http}: / /$ drive5.com/uparse/), and chimeric sequences were identified and removed using UCHIME. The taxonomy of each 16S rRNA gene sequence was analyzed by RDP Classifier (http: //rdp.cme.msu.edu/) against the SILVA (SSU115) 16S rRNA database using a confidence threshold of $70 \%$. Hierarchical clustering analysis was performed using Cluster and visualized using TreeView, and other statistical analyses were performed with the Institute for Environmental Genomics (IEG) pipeline (http://ieg.ou.edu). The average data were calculated for BSCs of each revegetation before analyzing the unique and shared OTUs/genera. The figures were generated with OriginPro 9.1 and Excel 2013. Alpha-diversity analysis was used to reflect the richness and diversity of microbial communities. In order to investigate the overall differences in community composition among the samples, principal component analysis (PCA) was performed using unweighted UniFrac distance (Lozupone and Knight, 2005). Redundancy 

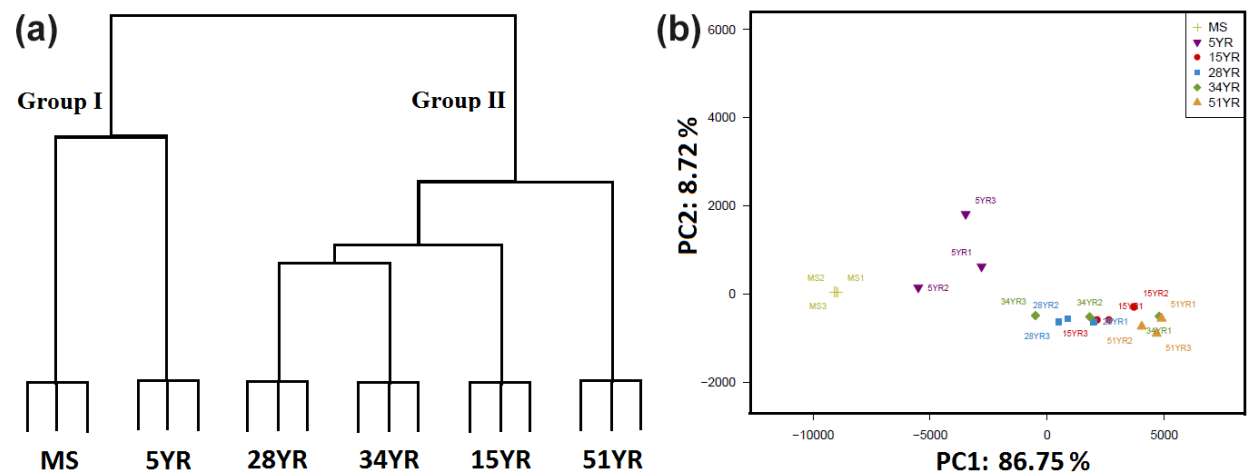

Figure 3. Hierarchical clustering analysis and PCA of bacterial communities in six different ages of BSCs at OTU level based on $97 \%$ similarity (triplicate samples for each age). MS, 5YR, 15YR, 28YR, 34YR and 51YR represent mobile sand, 5-, 15-, 28-, 34- and 51-yearold BSCs, respectively.

analysis (RDA) was used to assess the relationship between bacterial compositions of BSCs and top soil physicochemical properties by permutation test analysis (Zhang et al., 2016). Phylogenetic analysis of the top abundance genus was aligned with closely related 16S rRNA gene sequences, previously selected according to initial BLAST analyses and downloaded from the NCBI website (http://www.ncbi. nlm.nih.gov), using CLUSTAL W (Gundlapally and GarciaPichel, 2006). Phylogenetic trees were constructed using the approximately maximum likelihood routine by FastTree (version 2.1.3 http://www.microbesonline.org/fasttree/).

\section{Results}

\subsection{Overview of sequencing and bacterial diversity}

Illumina MiSeq sequencing was used to assess the bacterial community composition and diversity of BSCs in successional stages for revegetation in Shapotou. In total, 18 libraries of bacterial 16S rRNA were constructed, and at least 37332 effective sequences in each sample were obtained, with an average length of $437 \mathrm{bp}$. A total of 1197-2307 OTUs were generated using a threshold of 0.97 (Table S1 in the Supplement); 394 OTUs were shared and occupied a relatively high proportion among all samples (17.07-32.92\%) (Table S2), and these OTUs accounted for $41.96-84.88 \%$ of the total sequences (Table S2). This indicated a high coherence of community among these soil crusts. Alpha-diversity analysis revealed the microbial richness and diversity. Rarefaction curves showed that the most bacterial OTUs were found in 51YR crust, whereas MS contained the fewest. The number of OTUs was almost the same from 15YR to 51YR (Fig. 2). Community richness estimation using ACE and Chao revealed a similar trend to that for community diversity, which was further supported by Shannon's indexes (Table S1). Hierarchical clustering analysis (Fig. 3a) and PCA (Fig. 3b) showed that the triplicate samples of each age of
BSCs were clustered, verifying that the sequencing results were reliable and the samples were reproducible.

\subsection{Bacterial community composition at high taxonomic levels}

In the bacterial community, a total of 28 phyla were retrieved at genetic distances of $3 \%$ and clustered into four groups according to their relative abundance (Fig. 4). Of the total sequences, $4.48 \%$ were not classified at the phylum level. The percentages of major phyla for each age of BSCs are shown in Fig. 5. The most abundant phylum shifted from Firmicutes $(72.8 \%)$ in MS and 5YR to Actinobacteria in BSCs (minimum of $27.4 \%$ in $15 \mathrm{YR}$ and maximum of $30.7 \%$ in 51YR). The following major phyla were at high abundance ( $>10 \%$ of total OTUs): Proteobacteria, Chloroflexi, Acidobacteria and Cyanobacteria. The low-abundance phyla $(1 \%<$ of total OTUs $<10 \%)$ were Gemmatimonadetes, Bacteroidetes, Armatimonadetes, Verrucomicrobia and Deinococcus-Thermus. The percentages of Proteobacteria, Chloroflexi and Acidobacteria were nearly the same after 15 years of development of BSCs. Cyanobacteria, in addition to the high proportion for $15 \mathrm{YR}(16.13 \%)$, also had a high proportion in 51YR $(9.32 \%)$. The other 17 phyla were all $<1 \%$ of total OTUs and so were removed from further analysis.

At the class level (Table 1), $95.61 \%$ of sequences were assigned, and there was considerable consistency in dominant classes among the crusts. Bacilli was the largest class in MS and 5YR with sequence percentages of 68.73 and $32.62 \%$, respectively; Actinobacteria was the predominant class from $15 \mathrm{YR}$ to $51 \mathrm{YR}$. In addition to subdivisions of Proteobacteria, other major classes included Acidobacteria, Cyanobacteria, Chloroflexi, Clostridia, Cytophagia, Deinococci, Gemmatimonadetes, Ktedonobacteria, Sphingobacteria and Thermomicrobia. The percentages of highabundance ( $>10 \%$ of total OTUs) and low-abundance $(1 \%<$ of total OTUs $<10 \%)$ classes decreased from $98 \%$ in 
Table 1. Percentages of the major classes in each age of BSCs. MS, 5YR, 15YR, 28YR, 34YR and 51YR represent mobile sand, 5-, 15-, 28-, 34- and 51-year-old BSCs, respectively.

\begin{tabular}{lrrrrrr}
\hline Dominant & MS & 5 YR & $15 Y R$ & $28 Y R$ & $34 Y R$ & $51 Y R$ \\
\hline Bacilli & 68.73281 & 32.6217 & 10.87003 & 18.88014 & 14.65767 & 2.809922 \\
Actinobacteria & 10.25572 & 17.22651 & 27.36705 & 28.34208 & 29.31533 & 30.65824 \\
Alphaproteobacteria & 4.058181 & 12.26026 & 19.93375 & 16.30594 & 18.98282 & 21.11772 \\
Acidobacteria & 1.404514 & 2.372406 & 11.75488 & 8.32619 & 7.703847 & 9.022644 \\
Chloroflexia & 0.886639 & 2.423301 & 4.006393 & 2.962606 & 3.367977 & 3.857281 \\
Cyanobacteria & 0.112504 & 16.13272 & 3.943891 & 2.275974 & 2.367049 & 9.32444 \\
Clostridia & 4.091218 & 1.661666 & 0.517876 & 1.017893 & 0.704489 & 0.15447 \\
Cytophagia & 0.265188 & 1.223258 & 0.93039 & 0.739312 & 1.022358 & 1.579521 \\
Deinococci & 0.048216 & 1.255402 & 0.342869 & 0.372335 & 0.249116 & 0.20715 \\
Deltaproteobacteria & 0.447337 & 0.740205 & 1.150934 & 0.993785 & 1.087539 & 1.255402 \\
Gammaproteobacteria & 5.715383 & 2.632237 & 1.011643 & 1.890246 & 1.417015 & 0.425908 \\
Gemmatimonadetes & 0.645559 & 2.400979 & 2.406336 & 2.646523 & 2.75992 & 2.40455 \\
Ktedonobacteria & 0.053573 & 0.113397 & 1.75542 & 1.121469 & 2.072395 & 1.657202 \\
Sphingobacteriia & 0.262509 & 0.666095 & 1.200043 & 0.897353 & 0.995571 & 0.889317 \\
Thermomicrobia & 0.449123 & 1.351834 & 3.24208 & 3.414408 & 3.008143 & 2.810815 \\
Betaproteobacteria & 0.572342 & 0.789314 & 0.939319 & 1.021465 & 1.073253 & 1.11254 \\
Minor & 0.018688 & 0.039555 & 0.080851 & 0.08194 & 0.081753 & 0.085887 \\
Unclassified & 0.000911 & 0.00142 & 0.005018 & 0.005822 & 0.009866 & 0.02084 \\
\hline
\end{tabular}

MS to $89.29 \%$ in $51 \mathrm{YR}$, and minor and unclassified classes increased from $1.96 \%$ in MS to $10.67 \%$ in 51 YR.

At the family level, there were 133 identified families (data not shown), with the most abundant families being Bacillaceae, Enterococcaceae and Streptococcaceae (Table S3). Other dominant families were Geodermatophilaceae, JG34-KF-161, JG34-KF-361, Methylobacteriaceae, Micromonosporaceae, Bradyrhizobiaceae and Enterobacteriaceae.

\subsection{Characterization of major genera and species}

A large proportion of sequences were not assigned to any genera. Even for genera with relative abundance $>1 \%$ in any sample, unclassified sequences occupied a high proportion (4.87-8.59\%). Moreover, higher percentages of total sequences (from $13.51 \%$ in MS to $37.28 \%$ in $51 \mathrm{YR}$ ) were found in low-abundance genera $(<1 \%$ in any sample) (Table S4). A total of 460 genera were found in the crusts, of which 201 were shared by all BSC samples (data not shown). The major genera in each age of BSCs are summarized in Fig. 6. Bacillus, Enterococcus and Lactococcus were the primary genera; they represented $64.31 \%$ of the total sequences in MS, and decreased to $30.20 \%$ in $5 \mathrm{YR}$ and only $2.63 \%$ in $51 \mathrm{YR}$, indicating that these three genera were predominant in mobile sand or physical crusts. Enterobacteriaceae_unclassified and Alkaliphilus were low-abundance genera in MS. With the decrease in the three primary genera from MS to 51YR, a series of genera increased in BSCs compared with MS and 5YR, including RB41_norank, JG34-KF-361_norank, Acidimicrobiales_uncultured, JG34-KF-161_norank, JG30-
KF-CM45_norank, Microvirga, Actinobacteria_norank and Rubrobacter (relative abundance $>2 \%$ ).

The phylogenetic relationships of the 30 most abundant genera are shown in Fig. 7. They clustered into three groups at the phylum level: Actinobacteria formed one group and included 10 genera; another group was Firmicutes and Proteobacteria; and Cyanobacteria, Chloroflexi and Deinococcus-Thermus formed the third group. The genera Bryobacter and Blastocatella in phylum Acidobacteria were divided into two different groups.

Bacillus was the primary genus and represented $31 \%$ of the sequences in MS (Table S4). An unclassified species in this genus reached nearly $30 \%$ relative abundance in MS (Fig. 8). In the Enterococcus genus, another core component, there was also an unclassified species with high abundance. In the core species (Fig. 8), Bacillus_unclassified, Enterococcus_unclassified, Lactococcus piscium, Enterobacteriaceae_unclassified and Alkaliphilus oremlandii OhILAs were predominant and decreased from MS to 51YR; only Acidimicrobiales_unclassified increased, with the highest proportion in 51YR $(2.62 \%)$. The relative abundance of the primitive species in MS and physical crusts decreased in BSCs (from 15YR to 51YR) because of the increased numbers of species. There was little difference in numbers of genera and species among biocrusts (from 15YR to 51YR), only in sequence numbers.

\subsection{Relationships between bacterial community structure and soil physicochemical properties}

RDA (Fig. 9) and hierarchical clustering analysis (Fig. 3) were used to discern the correlations between bacterial com- 


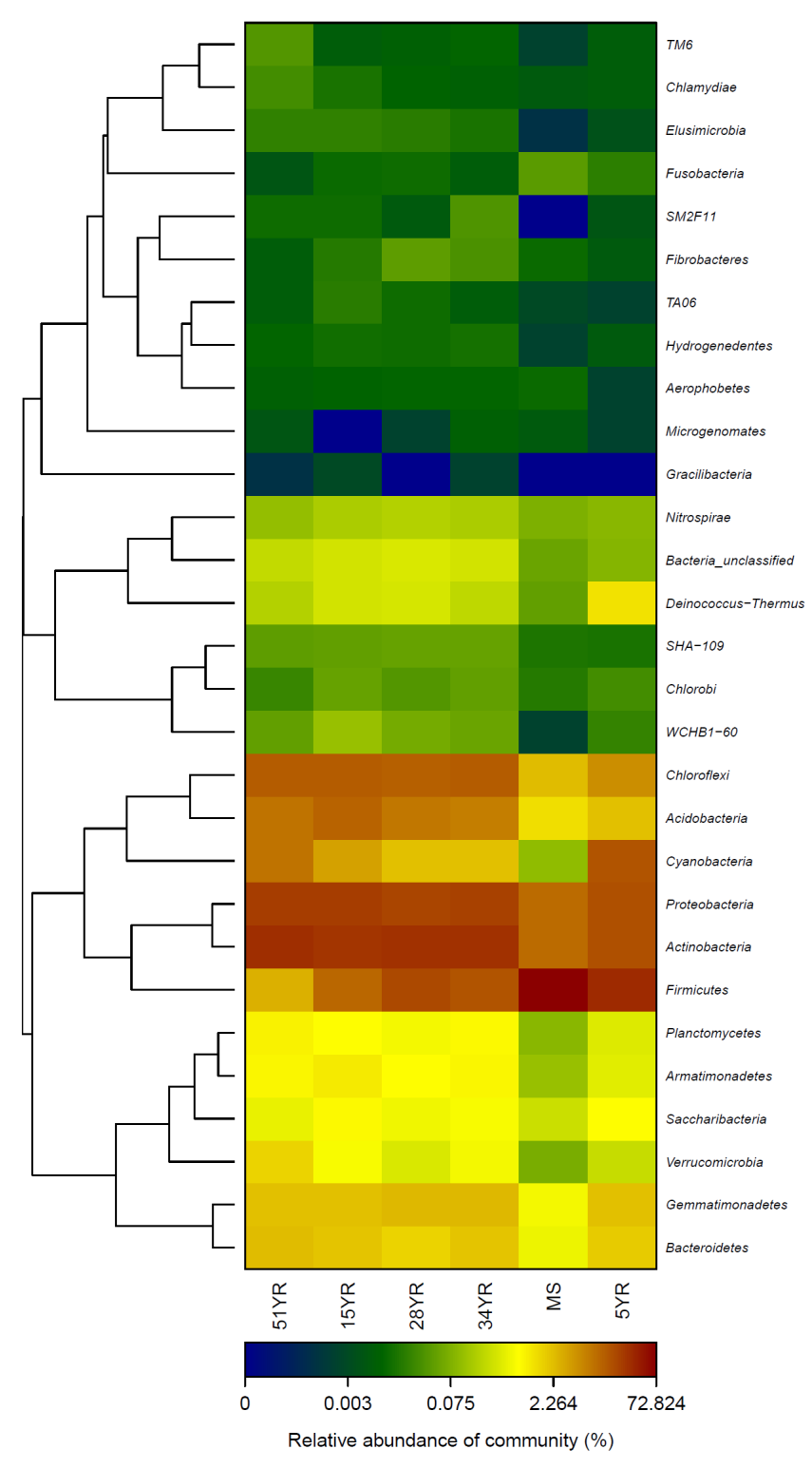

Figure 4. Heat map of bacterial communities in different ages of BSCs at phylum level. MS, 5YR, 15YR, 28YR, 34YR and 51YR represent mobile sand, 5-, 15-, 28-, 34- and 51-year-old BSCs, respectively.

munities and soil physicochemical properties. Taking into account the likely changes in the soil properties from samples with the same successional stages at the same experimental site, we selected soil biogeochemical data collected from 2005 in the RDA (data from Li et al., 2007a; Table S5). The BSC grouping patterns of bacterial communities at the phylum and genus levels were similar to the OTU level, with all divided into two groups. Group I contained two members, MS and 5YR, which dominated the physical crusts and algal crusts (Fig. 1a and b) and had the lowest diversities with Shannon indexes of 3.3 and 4.61, and Simpson indexes of
0.139 and 0.0531 , respectively (Table S1). The remaining BSCs comprised the largest branch of group II, which dominated BSCs composed of algae, lichens or mosses (Fig. 1c-f) and had higher diversity with Shannon indexes $>6.0$ (Table S1).

From Fig. 9, it can be inferred that BSC development was associated with soil physicochemical properties. The development of microbial community structure was positively correlated with the physicochemical index except for soil bulk density. The total variation in OTU data explained by the first four axes in the RDA (as constrained by the measured environmental variables) was $82.16 \%$, with the first axis explaining $75.27 \%$ and the second axis explaining $4.42 \%$. Of all the environmental factors, silt + clay content and total $\mathrm{K}$ were most strongly related to axis 1 , with highest correlated variable (silt + clay: -0.91 ; total $\mathrm{K}:-0.90$ ). Therefore, silt + clay content and total $\mathrm{K}$ were closely related to bacterial community development of BSCs, shown by the positions of cluster groups along axis 1 . Eight soil physicochemical variables were all significant as verified by the permutation test analysis $(P<0.05)$ : $\mathrm{pH}$; silt and clay content; organic $\mathrm{C}$; total phosphorus $(\mathrm{P})$, nitrogen $(\mathrm{N})$ and potassium (K); electrical conductivity (EC); and water-holding capacity (WHC).

\subsection{Quantification of bacterial abundance}

The averaged bacterial abundance in MS was $1.12 \times 10^{6}$ copies (16S rRNA gene) per gram of soil (Table 2). Similar to the shift of bacterial richness, gene copies increased quickly in the initial 15 years of BSC development and reached the approximate highest level of $2.70 \times 10^{8}$ copies in $15 \mathrm{YR}$. There were no significant differences among 28YR, 34YR and 51YR.

\section{Discussion}

On a landscape scale and in high-stress environments, the role of diversity hot spots of BSC microbes is crucial to establishing stability and regulating moisture and nutrient cycling (Bowker, 2007). Additionally, bacteria are the conduits between the larger BSC organisms and plants, facilitating micro-processes (Castillo-Monroy et al., 2011). Thus, bacteria are key contributors to the BSC primary succession process and no doubt also in terms of secondary succession.

\subsection{Impact of BSC age on bacterial community composition}

In the present study, we gained information concerning the diversity of bacterial communities in BSCs of different ages in restored vegetation in Shapotou in the Tengger Desert. The 16S rRNA gene-based amplicon survey revealed the dominance of Actinobacteria, Proteobacteria, Chloroflexi, Acidobacteria and Cyanobacteria in all BSCs, with Firmi- 


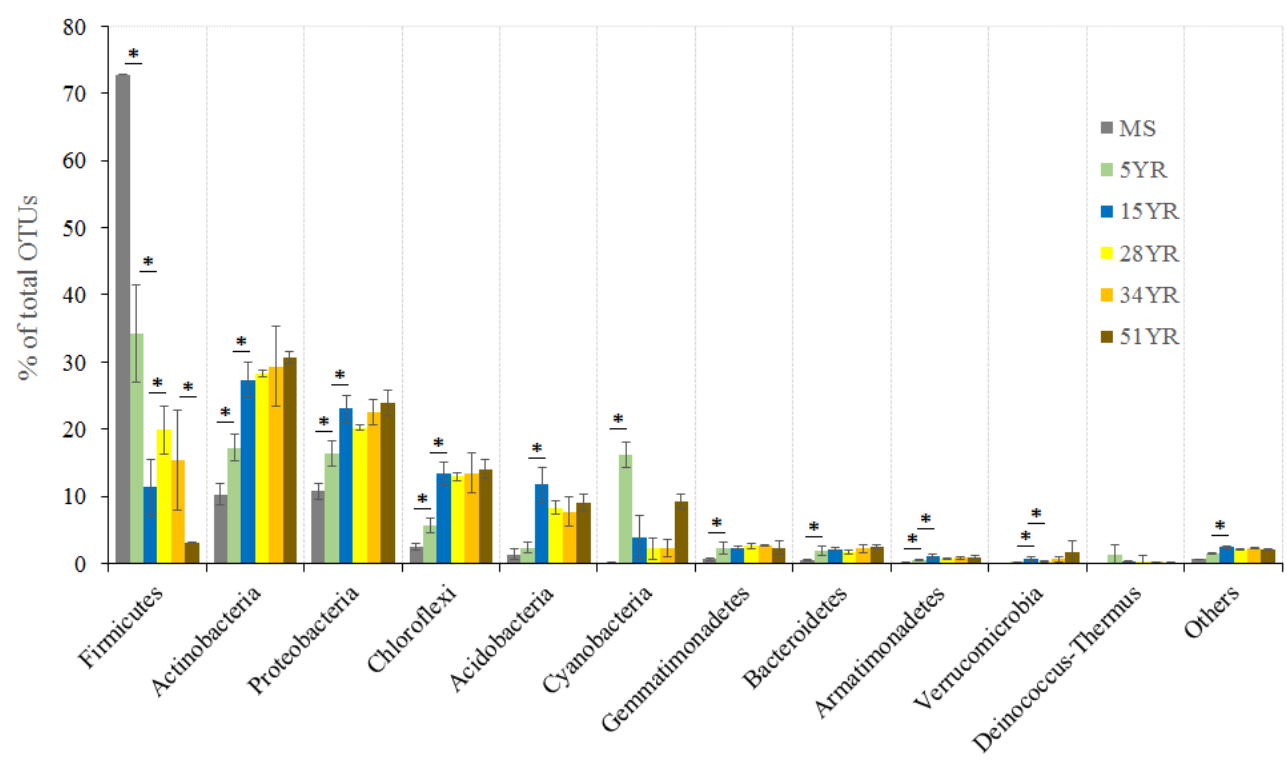

Figure 5. Abundant phyla ( $>10 \%$ of total OTUs) and low-abundance phyla $(1 \%<$ of total OTUs $<10 \%)$ of bacteria distributed in different ages of BSCs. Data are defined at a $3 \%$ OTU genetic distance. Data are presented as mean \pm standard deviation; $n=3$ per BSC sample. A paired $t$ test (BSC samples) was used to assess the significance between adjacent ages of BSCs. ${ }^{*} P \leq 0.05 ;{ }^{* *} P \leq 0.001$. MS, 5YR, 15YR, 28YR, 34YR and 51YR represent mobile sand, 5-, 15-, 28-, 34- and 51-year-old BSCs, respectively.

Table 2. Absolute abundances of bacteria (copies of ribosomal genes per gram of soil) in BSCs quantified by qPCR (means \pm standard deviation, $n=6)$. MS, 5YR, 15YR, 28YR, 34YR and 51YR represent mobile sand, 5-, 15-, 28-, 34- and 51-year-old BSCs, respectively.

\begin{tabular}{lcccccc}
\hline Dominant & MS & 5 YR & $15 Y R$ & $28 Y R$ & $34 Y R$ & 51 YR \\
\hline Bacteria abundance & $1.12 \times 10^{6}$ & $3.94 \times 10^{7}$ & $2.70 \times 10^{8}$ & $5.44 \times 10^{8}$ & $7.61 \times 10^{8}$ & $9.03 \times 10^{8}$ \\
& $\pm 4.19 \times 10^{5} \mathrm{a}$ & $\pm 2.21 \times 10^{6} \mathrm{~b}$ & $\pm 1.91 \times 10^{7} \mathrm{c}$ & $\pm 4.23 \times 10^{7} \mathrm{c}$ & $\pm 8.5 \times 10^{7} \mathrm{c}$ & $\pm 2.55 \times 10^{7} \mathrm{c}$
\end{tabular}

Means with different letters are significantly different $(P<0.05)$.

cutes dominating MS (72.8\%) and decreasing to $3.05 \%$ in 51YR, and Actinobacteria increasing from 15YR (27.4\%) to 51YR (30.7\%). Due to different arid conditions, comparisons with other studies of BSCs should be viewed with caution. Cyanobacteria, Actinobacteria, Proteobacteria and Acidobacteria are ubiquitous in soils and sediments everywhere, in arid as well as wet landscapes (Fierer et al., 2012), and Proteobacteria are very common and diverse among all BSCs. We observed that Actinobacteria were the most abundant phylum in the developing (15YR, 28YR and 34YR) and relatively developed (51YR) BSCs, similar to BSCs from the Colorado Plateau and the Sonoran Desert, where Actinobacteria were dominant (Gundlapally and Garcia-Pichel, 2006; Nagy et al., 2005; Steven et al., 2013). Actinobacteria and Proteobacteria are usually predicted to be copiotrophic groups which increase in high-C environments (Fierer et al., 2007). These results differ from those reported in BSCs from Oman and the Gurbantunggut Desert (Abed et al., 2010; Moquin et al., 2012; Zhang et al., 2016), and even from BSCs of natural vegetation at the edge of the Tengger Desert (Wang et al., 2015), where Proteobacteria were the most abundant phy- lum, followed by Cyanobacteria, Actinobacteria and Chloroflexi. Unexpectedly, Cyanobacteria had a high proportion in the developed BSCs, although they were prevalent in early successional stages of BSCs (5YR) and play crucial roles in initial crust development (Belnap and Lange, 2001). This is relatively similar to that in the natural habitat around the Tengger Desert, where Cyanobacteria $(19.5 \%)$ and Actinobacteria $(19.4 \%)$ were the most dominant phyla after Proteobacteria $(25.0 \%)$. Moreover, the results did not resemble those from arid Arizona soils (Dunbar et al., 1999) or the Gurbantunggut Desert (Zhang et al., 2016) due to the high proportion of Chloroflexi, an unexplained presence of thermophilic phyla (Gundlapally and Garcia-Pichel, 2006; Moquin et al., 2012; Nagy et al., 2005) that display good adaptation to drought conditions and the important roles in the development of BSCs in arid zones (Lacap et al., 2011; Wang et al., 2015). 

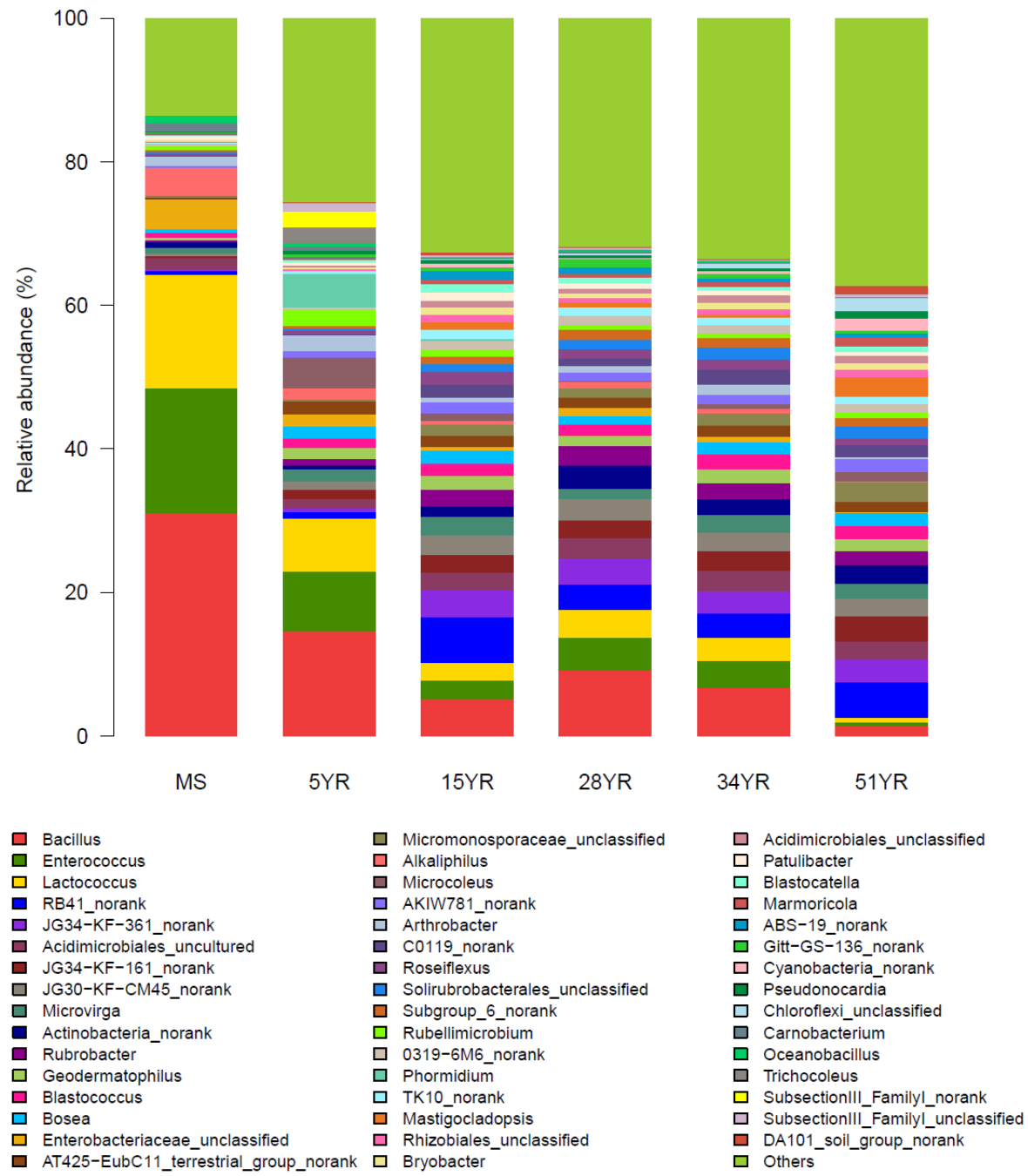

Figure 6. Bacterial community composition in six different ages of BSCs at the genus level. Data are defined at a $3 \%$ OTU genetic distance. MS, 5YR, 15YR, 28YR, 34YR and 51YR represent mobile sand, 5-, 15-, 28-, 34- and 51-year-old BSCs, respectively.

\subsection{Function of BSC bacteria}

More recent information about BSC bacteria has been reported with the convenience of culture-independent sequencing methods, and studies of their function and classification in BSCs are increasingly detailed. The main function of these dominant bacteria involves the cycling and storage of $\mathrm{C}$ and $\mathrm{N}$ in desert ecosystems, which is vital to the functioning of arid land (Weber et al., 2016). Firmicutes are more frequently detected in below-biocrust soils (1-2 cm depth) (Elliott et al., 2014) and dominated in MS and 5YR, with the vast majority of abundant species being in Firmicutes in the Tengger Desert. Cyanobacteria are the main contributors to $\mathrm{C}$ and $\mathrm{N}$ fixation in soils during successional processes of BSCs (Belnap and Gardner, 1993). They are thought to serve as pioneers in the stabilization process of soils (Garcia-Pichel and Wojciechowski, 2009), of which the genus Phormidium is significantly more abundant in surface soils $(0-1 \mathrm{~cm}$ depth), and the genus Microcoleus is globally dominant as biocrust-forming microorganisms in most arid lands, and their production of polysaccharide sheaths aids in the formation of centimeter-long filament bundles (Belnap and Lange, 2003; Boyer et al., 2002; Garcia-Pichel et al., 2001; Pointing and Belnap, 2012). In addition to the filamentous bacteria of Microcoleus and Phormidium, Mastigocladopsis and Trichocoleus were also in the 30 most abundant genera of BSCs in Shapotou and mainly harvest energy from light. Pseudonocardia, a mycelial genus of Actinobacteria, was dominant and is likely important during BSC formation (Weber et al., 2016). Proteobacteria and Bacteroidetes can produce exopolysaccharides, so they could also play roles in soil stabilization and BSC formation (Gundlapally and GarciaPichel, 2006).

Owing to limited culture collections and curated sequence databases of BSC bacteria, most non-cyanobacterial se- 


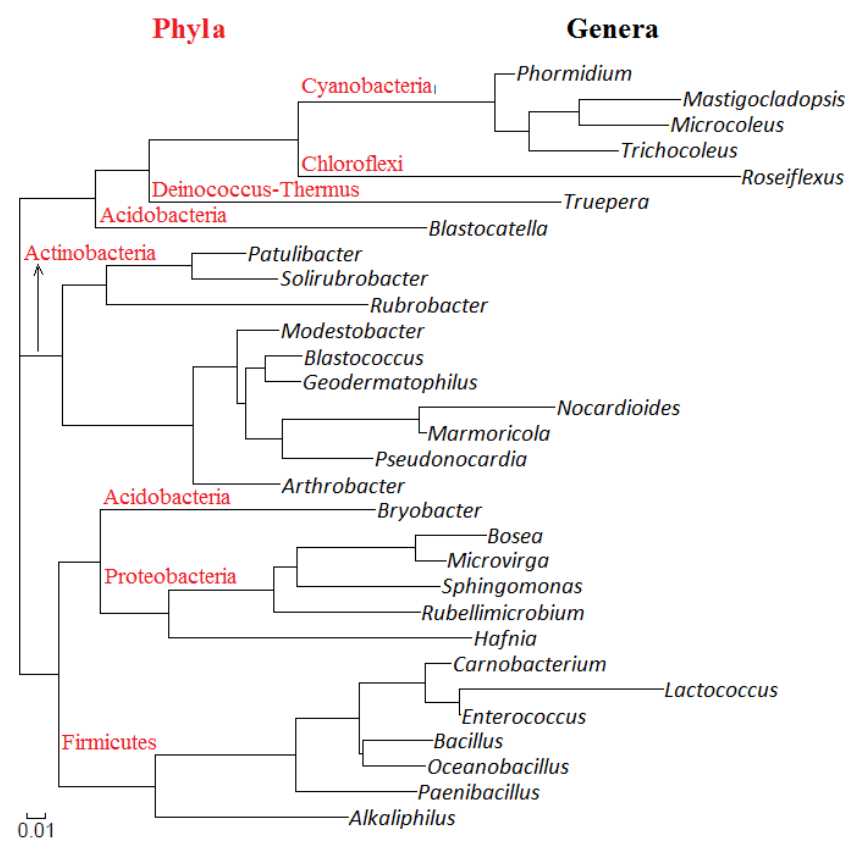

Figure 7. Phylogenetic relationship of the 30 most abundant genera in bacterial composition of BSCs.

quences from DNA-based bacterial surveys cannot be reliably named or taxonomically defined, especially in relatively abundant genera in Actinobacteria and Proteobacteria, such as Bosea, Microvirga, Rubellimicrobium, Patulibacter, Solirubrobacter, Blastococcus and Arthrobacter in the present study. Different compositions of bacterial communities play various roles in improving soil properties in different BSC successional stages, suggesting their positive potential function in soil biogeochemical cycle and ecosystem process. Further discovery and characterization of the functions of these dryland-adapted bacteria is a challenging area for future study.

\subsection{Relationship between bacterial community shift and soil physicochemical properties}

PCA and RDA showed that bacterial community compositions of MS and 5YR significantly differed from those of BSCs of more than 15 years in age and were positively correlated with soil physicochemical properties. Combined with the results of alpha-diversity analysis and qPCR, this means that the species richness and abundance reached their highest levels at 15 years of BSC development and then maintained similar levels thereafter. Similar trends were found in recovery of soil properties and processes after sand binding at five different-aged revegetated sites - proportions of silt and clay, and organic $\mathrm{C}$ increased with years since revegetation ( $\mathrm{Li}$ et al., 2007a, b). The annual recovery rates of soil properties were greater at the initial revegetated sites ( $0-14$ years) than at the old revegetated sites (43-50 years) ( $\mathrm{Li}$ et al., 2007a).
These results suggest that bacterial communities of BSCs recovered quickly in the fastest recovery phase of soil properties (the initial 15 years), and the bacterial biomass increased with the improvement of soil texture and nutrients, especially silt, clay and total $\mathrm{K}$ content in the Tengger Desert. A significant positive correlation was found between silt and clay and the number of BSC types in southern Africa (Büdel et al., 2009), suggesting that fine grain size promotes BSC succession and their biomass content. This may be attributed to the diversity of BSCs, vegetation composition, soil temperature and soil moisture, because these are key factors regulating soil microbial composition and activity (Butenschoen et al., 2011; De Deyn et al., 2009; Sardans et al., 2008), soil nutrient uptake and release (Peterjohn et al., 1994; Rustad et al., 2001), especially in the BSCs of top soil. It would be good to understand more of the factors that together influenced the composition and function of BSC bacteria in long-term revegetation, including BSCs, plants, soil biochemical properties and climate conditions, and the microorganisms that in turn have the positive influence on soil improvement ( $\mathrm{Li}$ et al., 2007b, 2010).

Many reports have interpreted correlations among soil properties and BSCs as an indicator that BSCs are drivers of soil fertility and development (Chamizo et al., 2012; Delgado-Baquerizo, 2013; Yu et al., 2014; Zhang et al., 2010); some have reported the opposite and suggest a direct influence of soil properties on BSC development (Belnap et al., 2014; Bowker et al., 2006a; Bowker and Belnap, 2008; Concostrina-Zubiri et al., 2013; Rivera-Aquilar et al., 2009; Root and McCune, 2012; Weber et al., 2016). These are important questions, and parsing out the interactions of BSCs and soil biogeochemical properties remains an important frontier in BSC research. However, further work to identify controlled experimental approaches is required because field correlations do not explain the directionality of causality over time.

\subsection{The role of BSCs in succession}

In temperate desert regions, BSCs are not well investigated regarding community structure and diversity. Furthermore, studies on succession are rare (Langhans et al., 2009). Most evidence indicates that BSC facilitate succession to later series, suggesting that assisted recovery of BSCs could speed up succession (Bowker, 2007). Because BSCs are ecosystem engineers in high-abiotic-stress systems, loss of BSCs may be synonymous with crossing degradation thresholds. Whether BSCs are deemed facilitative or inhibitory for later successional vegetation may depend on how exhaustively the interaction between plants and BSCs is investigated. In fixedsand areas, BSCs may in some cases reduce infiltration (inhibitory effect) (Mitchell et al., 1998), but they also increase soil stability and serve as an $\mathrm{N}$ source for surviving and recolonizing trees (facilitative effects) (Tateno et al., 2003; Uchida et al., 2000). The BSC bacterial communities in the 


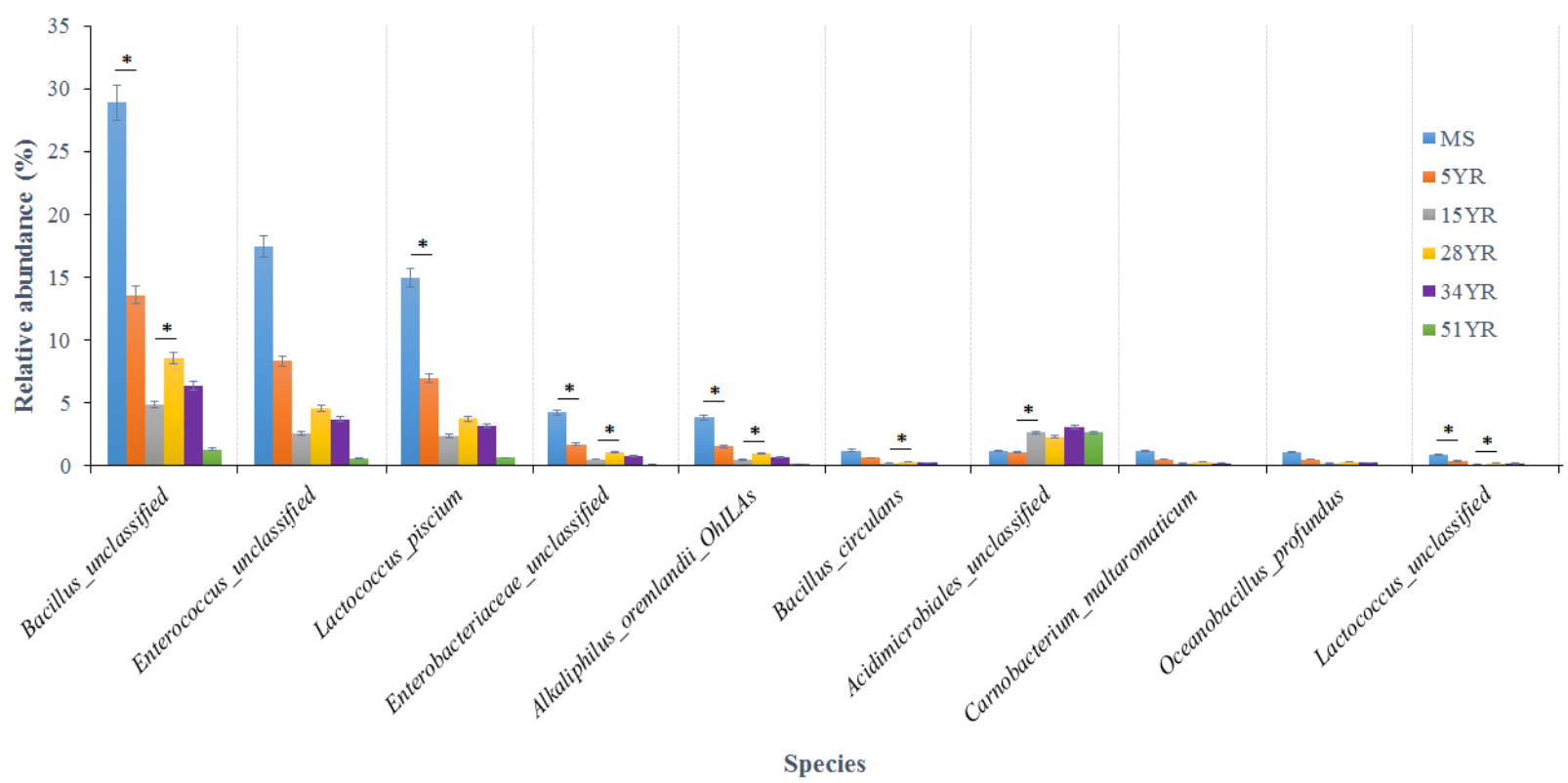

Figure 8. Abundant species ( $>10 \%$ of total OTUs) and low-abundance species $(1 \%<$ of total OTUs $<10 \%)$ of bacteria distributed in different ages of BSCs. Data are defined at a $3 \%$ OTU genetic distance. Data are presented as mean \pm standard deviation; $n=3$ per BSC samples. Paired $t$ tests (BSC samples) were used to assess the significance between the adjacent ages of BSCs. ${ }^{*} P \leq 0.05$; ${ }^{* *} P \leq 0.001$. MS, 5YR, 15YR, 28YR, 34YR and 51YR represent mobile sand, 5-, 15-, 28-, 34- and 51-year-old BSCs, respectively.

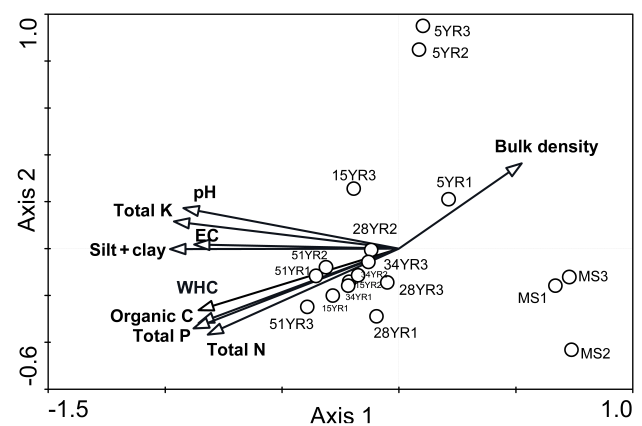

Figure 9. Redundancy analysis (RDA) of bacterial community structures in relation to soil physiochemical properties. Arrows indicate the direction and magnitude of soil physiochemical index associated with bacterial community structures. The lengths of arrows in the RDA plot correspond to the strength of the correlation between variables and community structure. Each circle represents the bacterial community structure for each sample.

successional stages may help establish stability and regulate nutrient and biogeochemical cycling. Castillo-Monroy et al. (2011) found that the BSC richness matrix had the greatest direct effect on the ecosystem function matrix. Despite this result, very few of the BSC effects on ecosystem function could be ascribed to changes within the bacterial community. This provides valuable insights concerning semiarid ecosystems where plant cover is spatially discontinuous and ecosystem function in plant interspaces is regulated largely by BSCs.

\section{Conclusions}

Illumina MiSeq sequencing showed that changes of BSC bacterial diversity and richness in BSC succession were consistent with the recovery phase of soil properties in vegetation succession of Shapotou in the Tengger Desert. The shift of bacterial community composition in BSCs at all levels of classification was related to their corresponding function in the BSC recovery process. BSC bacteria are crucial to establishing stability and nutrient cycling in desert ecosystem, and they are the conduits between the larger BSC organisms and plants facilitating micro-processes. These results have confirmed that bacteria are key contributors to the BSC succession process.

Data availability. Raw data for Illumina MiSeq sequencing of 18 samples were deposited in the NCBI Sequence Read Archive database (https://www.ncbi.nlm.nih.gov/sra/?term=SRP090538).

\section{The Supplement related to this article is available online at https://doi.org/10.5194/bg-14-3801-2017-supplement.}

Author contributions. LL and YL designed the research. PZ, GS and RH collected samples from the field. YL and JW performed DNA extraction and quality detection. YL analyzed the highthroughput data and prepared the manuscript with consistent con- 
tributions from LL. ZW analyzed the soil biogeochemical data and made the RDA figure.

Competing interests. The authors declare that they have no conflict of interest.

Special issue statement. This article is part of the special issue " $\mathrm{Bi}$ ological soil crusts and their role in biogeochemical processes and cycling”. It is not associated with a conference.

Acknowledgements. This work was financially supported by the Creative Research Group Program of the National Natural Science Foundation of China (grant no. 41621001) and the National Natural Science Foundation of China (grant nos. 41371100 and 41401112).

Edited by: Anita Antoninka

Reviewed by: two anonymous referees

\section{References}

Abed, R. M. M., Kharusi, S. A., Schramm, A., and Robinson, M. D.: Bacterial diversity, pigments and nitrogen fixation of biological desert crusts from the Sultanate of Oman, FEMS Microbiol. Ecol., 72, 418-428, 2010.

Albiach, R., Canet, R., Pomares, F., and Ingelmo, F.: Microbial biomass content and enzymatic activities after the application of organic amendments to a horticultural soil, Bioresour. Technol., 75, 43-48, 2000.

Baldrian, P., Merhautova, V., Petrankova, M., and Cajthaml, T.: Distribution of microbial biomass and activity of extracellular enzymes in a hardwood forest soil reflect soil moisture content, Appl. Soil Ecol., 46, 177-182, 2010.

Balser, T. and Firestone, M.: Linking microbial community composition and soil processes in a California annual grassland and mixed-conifer forest, Biogeochemistry, 73, 395-415, 2005.

Bates, S. T., Nash, T. H., Sweat, K. G., and Garcia-Pichel, F.: Fungal communities of lichen-dominated biological soil crusts: Diversity, relative microbial biomass, and their relationship to disturbance and crust cover, J. Arid Environ., 74, 1192-1199, 2010.

Bates, S. T., Cropsey, G. W., Caporaso, J. G., and Knight, R.: Bacterial communities associated with the lichen symbiosis, Appl. Environ. Microbiol., 77, 1309-1314, 2011.

Belnap, J.: The world at your feet: desert biological soil crusts, Front Ecol. Environ., 1, 181-189, 2003.

Belnap, J.: The potential roles of biological soil crusts in dryland hydrologic cycles, Hydrol. Process., 20, 3159-3178, 2006.

Belnap, J. and Eldridge, D.: Disturbance and recovery of biological soil crusts, in: Biological soil crusts: structure, function, and management, ecological studies, edited by: Belnap, J. and Lange, O. L., Vol. 150, Springer, Berlin, 363-383, 2003.

Belnap, J. and Gardner, J. S.: Soil microstructure in soils of the Colorado Plateau: the role of the cyanobacterium Microcoleus vaginatus, Great Basin Nat., 53, 40-47, 1993.

Belnap, J. and Lange, O. L.: Biological Soil Crusts: Structure, Function, and Management, Springer-Verlag, Berlin, Germany, 2001.
Belnap, J., Miller, D. M., Bedford, D. R., and Phillips, S. L.: Pedological and geological relationships with soil lichen and moss distribution in the eastern Mojave Desert, CA, USA, J. Arid Environ., 106, 45-57, 2014.

Bowker, M. A.: Biological soil crust rehabilitation in theory and practice: an underexploited opportunity, Restor. Ecol., 15, 1323, 2007.

Bowker, M. A. and Belnap J.: A simple classification of soil types as habitats of biological soil crusts on the Colorado Plateau, USA, J. Veg. Sci., 19, 831-840, 2008.

Bowker, M. A., Belnap, J., Davidson, D. W., and Goldstein, H.: Correlates of biological soil crust abundance across a continuum of spatial scales: support for a hierarchical conceptual model, J. Appl. Ecol., 43, 152-163, 2006a.

Bowker, M. A., Belnap, J., and Miller, M. E.: Spatial modeling of biological soil crusts to support rangeland assessment and monitoring, Rangeland Ecol. Manage, 59, 519-529, $2006 \mathrm{~b}$.

Bowker, M. A., Maestre, F. T., and Escolar, C.: Biological crusts as a model system for examining the biodiversity-ecosystem function relationship in soils, Soil Biol. Biochem., 42, 405-417, 2010.

Boyer, S. L., Johansen, J. R., Flechtner, V. R., and Howard, G. L.: Phylogeny and genetic variance in terrestrial Microcoleus (Cyanophyceae) species based on sequence analysis of the 16S rRNA gene and associated 16S-23S ITS region, J. Phycol., 38, 1222-1235, 2002.

Büdel, B., Darienko, T., Deutschewitz, K., Dojani, S., Friedl, T., Mohr, K. I., Salisch, M., Reisser, W., and Weber, B.: Southern African biological soil crusts are ubiquitous and highly diverse in drylands, being restricted by rainfall frequency, Microb. Ecol., 57, 229-247, 2009.

Butenschoen, O., Scheu, S., and Eisenhauer, N.: Interactive effects of warming, soil humidity and plant diversity on litter decomposition and microbial activity, Soil Biol. Biochem., 43, 19021907, 2011.

Cardinale, M., Castro Jr., J. V., Müller, H., Berg, G., and Grube, M.: In situ analysis of the bacterial community associated with the reindeer lichen Cladonia arbuscula reveals predominance of Alphaproteobacteria, FEMS Microbiol. Ecol., 66, 63-71, 2008.

Castillo-Monroy, A. P., Bowker, M. A., Maestre, F. T., RodriguezEcheverria, S., Martinez, I., Barraza-Zepeda C. E., and Escolar, C.: Relationships between biological soil crusts, bacterial diversity and abundance, and ecosystem functioning: Insights from a semi-arid Mediterranean environment, J. Veg. Sci., 22, 165-174, 2011.

Chamizo, S., Cantón, Y., Miralles, I., and Domingo, F.: Biological soil crust development affects physicochemical characteristics of soil surface in semiarid ecosystems, Soil Biol. Biochem., 49, 96105, 2012.

Concostrina-Zubiri, L., Huber-Sannwald, E., Martínez, I., Flores, J. L., and Escudero, A.: Biological soil crusts greatly contribute to small-scale soil heterogeneity along a grazing gradient, Soil Biol. Biochem., 64, 28-36, 2013.

De Deyn, G. B., Quirk, H., Yi, Z., Oakley, S., Ostle, N. J., and Bardgett, R. D.: Vegetation composition promotes carbon and nitrogen storage in model grassland communities of contrasting soil fertility, J. Ecol., 97, 864-875, 2009.

Delgado-Baquerizo, M., Morillas, L., Maestre, F. T., and Gallardo, A.: Biocrusts control the nitrogen dynamics and microbial func- 
tional diversity of semi-arid soils in response to nutrient additions, Plant Soil, 372, 643-654, 2013.

Dunbar, J., Takala, S., Barns, S. M., Davis, J. A., and Kuske, C. R.: Levels of bacterial community diversity in four arid soils compared by cultivation and $16 \mathrm{~S}$ rRNA gene cloning, Appl. Environ. Biol., 65, 1662-1669, 1999.

Eldridge, D. J. and Greene, R. S. B.: Microbiotic soil crusts - a review of their roles in soil and ecological processes in the rangelands of Australia, Aust. J. Soil Res., 32, 389-415, 1994.

Elliott, D. R., Thomas, A. D., Hoon, S. R., and Sen, R.: Niche partitioning of bacterial communities in biological crusts and soils under grasses, shrubs and trees in the Kalahari, Biodivers. Conserv., 23, 1709-1733, 2014.

Evans, R. D. and Lange, O. L.: Biological soil crusts and ecosystem nitrogen and carbon dynamics, in: Biological Soil Crusts: Structure, Function, and Management, edited by: Belnap, J. and Lange, O. L., Springer, New York, 263-279, 2003.

Fierer, N., Bradford, M. A., and Jackson, R. B.: Toward an ecological classification of soil bacteria, Ecology, 88, 1354-1364, 2007.

Fierer, N., Leff, J. W., Adams, B. J., Nielsen, U. N., Bates, S. T., Lauber, C. L., Owens, S., Gilbert, J. A., Wall, D. H., and Caporaso, G. J.: Cross-biome metagenomic analyses of soil microbial communities and their functional attributes, P. Natl. Acad. Sci. USA, 109, 21390-21395, 2012.

Garcia-Pichel, F. and Wojciechowski, M. F.: The evolution of a capacity to build supra-cellular ropes enabled filamentous cyanobacteria to colonize highly erodible substrates, PLoS One, 4, e7801, https://doi.org/10.1371/journal.pone.0007801, 2009.

Garcia-Pichel, F., López-Cortés, A., and Nübel, U.: Phylogenetic and morphological diversity of cyanobacteria in soil desert crusts from the Colorado Plateau, Appl. Environ. Microb., 67, 19021910, 2001.

Green, L. E., Porras-Alfaro, A., and Sinsabaugh, R. L.: Translocation of nitrogen and carbon integrates biotic crust and grass production in desert grassland, J. Ecol., 96, 1076-1085, 2008.

Gundlapally, S. R. and Garcia-Pichel, F.: The community and phylogenetic diversity of biological soil crusts in the Colorado Plateau studied by molecular fingerprinting and intensive cultivation, Microb. Ecol., 52, 345-357, 2006.

Housman, D. C., Powers, H. H., Collins, A. D., and Belnap, J.: Carbon and nitrogen fixation differ between successional stages of biological soil crustsinthe Colorado Plateau and Chihuahuan Desert, J. Arid Environ., 66, 620-634, 2006.

$\mathrm{Hu}, \mathrm{C}$. X. and Liu, Y. D.: Primary succession of algal community structure in desert soil, Acta Bot. Sin., 45, 917-924, 2003.

Lacap, D. C., Warren-Rhodes, K. A., McKay, C. P., and Pointing, S. B.: Cyanobacteria and chloroflexi-dominated hypolithic colonization of quartz at the hyper-arid core of the Atacama Desert, Chile, Extremophiles, 15, 31-38, 2011.

Lan, S. B., Wu, L., Zhang, D. L., and Hu, C. X.: Successional stages of biological soil crusts and their microstructure variability in Shapotou region (China), Environ. Earth Sci., 65, 77-88, 2012a.

Lan, S. B., Wu, L., Zhang, D. L., and Hu, C. X.: Effects of drought and salt stresses on man-made cyanobacterial crusts, Eur. J. Soil Biol., 46, 381-386, 2012b.

Langhans, T. M., Storm, C., and Schwabe, A.: Community assembly of biological soil crusts of different successional stages in a temperate sand ecosystem, as assessed by direct determination and enrichment techniques, Microb. Ecol., 58, 394-407, 2009.
Li, X. R.: Eco-hydrology of biological soil crusts in desert regions of China, China Higher Education Press, 2012.

Li, X. R., He, M. Z., Duan, Z. H., Xiao, H. L., and Jia, X. H.: Recovery of topsoil physicochemical properties in revegetated sites in the sand-burial ecosystems of the Tengger Desert, northern China, Geomorphology, 88, 254-265, 2007a.

Li, X. R., Kong, D. S., Tan, H. J., and Wang, X. P.: Changes in soil and vegetation following stabilization of dunes in the southeastern fringe of the Tengger Desert, Plant Soil, 300, 221-231, 2007b.

Li, X. R., Tian, F., Jia, R. L., Zhang, Z. S., and Liu, L. C.: Do biological soil crusts determine vegetation changes in sandy deserts? Implications for managing artificial vegetation, Hydrol. Process., 24, 3621-3630, 2010.

Liu, L., Li, S., Duan, Z., Wang, T., Zhang, Z., and Li, X.: Effects of microbiotic crusts on dew deposition in the artificial vegetation area at Shapotou, northwest China, J. Hydrol., 328, 331-337, 2006.

Liu, L. C., Liu, Y. B., Hui, R., and Xie, M.: Recovery of microbial community structure of biological soil crusts in successional stages of Shapotou desert revegetation, northwest China, Soil Biol. Biochem., 107, 125-128, 2017.

Liu, Y., Li, X., Xing, Z., and Zhao, X.: Responses of soil microbial biomass and community composition to biological soil crusts in the revegetated areas of the Tengger Desert, Appl. Soil Ecol., 65, 52-59, 2013.

Lozupone, C. and Knight, R.: UniFrac: a new phylogenetic method for comparing microbial communities, Appl. Environ. Microbiol., 71, 8228-8235, 2005.

Maier, S., Schmidt, T. S. B., Zheng, L., Peer, T., Wagner, V., and Grube, M.: Analyses of dryland biological soil crusts highlight lichens as an important regulator of microbial communities, Biodivers Conserv., 23, 1735-1755, 2014.

Mitchell, D. J., Fullen, M. A., Trueman, I. C., and Fearnhough, W.: Sustainability of reclaimed desertified land in Ningxia, China, J. Arid. Environ., 39, 239-251, 1998.

Moquin, S. A., Garcia, J. R., Brantley, S. L., Takacs-Vesbach, C. D., and Shepherd, U. L.: Bacterial diversity of bryophyte-dominant biological soil crusts and associated mites, J. Arid Environ., 87 110-117, 2012.

Nagy, M. L., Perez, A., and Garcia-Pichel, F.: The prokaryotic diversity of biological soil crusts in the Sonoran Desert (Organ Pipe Cactus National Monument, AZ), FEMS Microbiol. Ecol., 54, 233-245, 2005.

Peterjohn, W. T., Melillo, J. M., and Steudler, P. A.: Responses of trace gas fluxes and $\mathrm{N}$ availability to experimentally elevated soil temperature, Ecol. Appl., 4, 617-625, 1994.

Pointing, S. B. and Belnap, J.: Microbial colonization and controls in dryland systems, Nat. Rev. Microbiol., 10, 551-562, 2012.

Rivera-Aguilar, V., Godínez-Alvarez, H., Moreno-Torres, R., and Rodríguez-Zaragoza, S.: Soil physico-chemical properties affecting the distribution of biological soil crusts along an environmental transect at Zapotitlán drylands, Mexico, J. Arid Environ., 73, 1023-1028, 2009.

Rustad, L. E., Campbell, J. L., Marion, G. M., Norby, R. J., Mitchell, M. J., Hartley, A. E., Cornelissen, J. H. C., and Gurevitch, J.: A meta-analysis of the response of soil respiration, net nitrogen mineralization, and aboveground plant growth to experimental ecosystem warming, Oecologia, 126, 543-562, 2001. 
Root, H. T. and McCune, B.: Regional patterns of biological soil crust lichen species composition related to vegetation, soils, and climate in Oregon, USA, J. Arid Environ., 79, 93-100, 2012.

Sardans, J., Penuelas, J., and Estiarte, M.: Changes in soil enzymes related to $\mathrm{C}$ and $\mathrm{N}$ cycle and in soil $\mathrm{C}$ and $\mathrm{N}$ content under prolonged warming and drought in a Mediterranean shrubland, Appl. Soil Ecol., 39, 223-235, 2008.

Steven, B., Gallegos-Graves, L. V., Belnap, J., and Kuske, C. R.: Dryland soil microbial communities display spatial biogeographic patterns associated with soil depth and soil parent material, FEMS Microbiol. Ecol., 86, 1-13, 2013.

Tateno, R., Katagiri, S., Kawaguchi, H., Nagayama, Y., Li, C., Sugimoto, A., and Koba, K.: Use of foliar ${ }^{15} \mathrm{~N}$ and ${ }^{13} \mathrm{C}$ abundance to evaluate effects of microbiotic crust on nitrogen and water utilization in Pinus massoniana in deteriorated pine stands of south China, Ecol. Res., 18, 279-286, 2003.

Uchida, T., Ohte, N., Kimoto, A., Mizuyama, T., and Chnaghua, L.: Sediment yield on a devastated hill in southern China: effects of microbiotic crust on surface erosion process, Geomorphology, 32, 129-145, 2000.

Wang, J., Bao, J., Su, J., Li, X., Chen, G., and Ma, X.: Impact of inorganic nitrogen additions on microbes in biological soil crusts, Soil Biol. Biochem., 88, 303-313, 2015.

Weber, B., Büdel, B., and Belnap, J.: Biological Soil Crusts: An Organizing Principle in Drylands, Ecological studies 226, Springer International Publishing, Switzerland, 2016.
Yeager, C. M., Kornosky, J. L., Housman, D. C., Grote, E. E., Belnap, J., and Kuske, C. R.: Diazotrophic community structure and function in two successional stages of biological soil crusts from the Colorado Plateau and Chihuahuan Desert, Appl. Environ. Microbiol., 70, 973-983, 2004.

Yu, J., Glazer, N., and Steinberger, Y.: Carbon utilization, microbial biomass, and respiration in biological soil crusts in the Negev Desert, Biol. Fertil. Soils, 50, 285-293, 2014.

Zhang, B., Kong, W., Wu, N., and Zhang, Y.: Bacterial diversity and community along the succession of biological soil crusts in the Gurbantunggut Desert, Northern China, J. Basic Microb., 56, 670-679, 2016.

Zhang, B. C., Zhang, Y. M., Zhao, J. C., and Wu, N.: Microalgal species variation at different successional stages in biological soil crusts of the Gurbantunggut Desert, Northwestern China, Biol. Fert. Soils, 45, 539-547, 2009.

Zhang, Y. M.: The microstructure and formation of biological soil crust in their early developmental stage, Chinese Sci. Bull., 50, 117-121, 2005.

Zhang, Y. M., Wu, N., Zhang, B. C., and Zhang, J.: Species composition, distribution patterns and ecological functions of biological soil crusts in the Gurbantunggut Desert, J. Arid Land, 2, 180 189, 2010. 